\title{
Novelpolyvinyl chloride-grafted-poly (ethylene imine) membranes for water treatment applications: Synthesis and membrane characterizations
}

\author{
Mohamed S. Mohy El-din ${ }^{1}$, Mahmoud Abdel Ghafar ${ }^{2}$, Abd El GawadRabiea ${ }^{3}$, Hossam A. Tieama ${ }^{1}$, \\ ${ }^{1}$ Polymer Materials Research Department, Advanced Technology and New Materials Research Institute (ATNMRI), City of Scientific \\ Research \& Technological Applications, New Borg Al-Arab City, Alexandria, Egypt \\ ${ }^{2}$ Chemistry Department, Polymers Department, National Research Center, Dokki, Giza, Egypt \\ ${ }^{3}$ Chemistry Department, Organic Chemistry, Faculty of Science, Ain Shams University, Cairo, Egypt
}

Email address:

h_tieama@yahoo.com (H. A. Tieama)

\section{To cite this article:}

Mohamed S. Mohy El-din, Mahmoud Abdel Ghafar, Abd El GawadRabiea, Hossam A. Tieama. Novelpolyvinyl Chloride-Grafted-Poly (Ethylene Imine) Membranes for Water Treatment Applications: Synthesis and Membrane Characterizations. American Journal of Applied Chemistry. Special Issue: Nano-technology for Environmental Aspects. Vol. 3, No. 3-1, 2015, pp. 13-21.

doi: 10.11648/j.ajac.s.2015030301.13

\begin{abstract}
Novel polyvinyl chloride grafted poly (ethylene imine), PVC-g-PEI membranes have been successfully synthesized by solvent evaporation technique using THF/ethanol as a solvent mixture. PEI was incorporated into PVC in different portions to increase the weak hydrophilicity of PVC membranes and to enhance physicochemical membranes surface properties. Membranes preparation conditions of PVC-g-PEI and their applications for water desalination process were optimized and discussed in details. PVC-g-PEI membranes were characterized by FTIR, morphologically using SEM, thermally using TGA\&DSC, and mechanically using universal testing machine. Poly (ethylene glycol), PEG was then added to PVC-g-PEI membranes as a pore forming additive to increase pores density area and improve efficiency of the permeation flux of membranes. Addition of PEG portions increased permeation flux of PVC-g-PEI membranes $\left(452 \mathrm{~L} / \mathrm{D} / \mathrm{M}^{2} 513 \mathrm{~L} / \mathrm{D} / \mathrm{M}^{2}\right.$ and605 $\left.\mathrm{L} / \mathrm{D} / \mathrm{M}^{2}\right)$ and salt rejection performance for mono membrane (33.5\%, 30.8\%and $27.4 \%$ ) for $3 \%, 2 \%$ and $1 \%$ NaCl solutions, respectively. Ion Exchange Capacity (IEC) for (PVC-g-PEI) membrane was 2.3 meq/gm and water uptake was $23 \%$.All filtration experiments results were carried out at a trans-membrane pressure of $0.3 \mathrm{MPa}$ at room temperature. The results showed that the permeate quality and quantity almost stable upon long run, thus PVC-g-PEI membranes can be used effectively for water treatment applications e.g. Nano-filtration and desalination.
\end{abstract}

Keywords: PVC-g-PEI Membranes, Salt Rejection, Permeation Flux, Desalination Membranes, Membrane Synthesis and Characterization

\section{Introduction}

Desalination, by definition, refers to the process of removing salt from seawater or brackish water. In a broader sense of the definition, desalination can also be inferred as removal of various inorganic ions from solution with the final target so as to produce clean and potable water. Nano-filtration (NF) as a subset of membrane processes have found wide application within this purview of desalination NF for example has been used in a desalination plant as pretreatment to both reverse osmosis ( $\mathrm{RO})$ and thermal processes, resulting in enhanced production of desalted seawater and reduced cost, yet remains an environmentally friendly process[1]. However, hydrophobic membranes are very susceptible to fouling by the adsorption of solutes in the feed, resulting in a decrease of flux [2]. It is possible to overcome this problem by the provision of hydrophilic character to the membrane surface. Since, surface properties are very important because the interaction between a polymeric membrane and its environment occurs chiefly at the surface [3].Polyvinyl chloride (PVC) is an outstanding hydrophobic membrane material because of its stiffness, low cost, excellent physical and chemical properties, as well as its robust mechanical strength [4]. PVC is a competitive resin with the virtues of abrasive resistance, acid and alkali resistance, microbial corrosion resistance, and chemical 
performance stabilization. PVC is also a promising ultra-filtration (UF) and microfiltration membrane material for water treatment. The solubility and miscibility of membrane polymer components are important parameters and should be taken in account during membrane design. Despite, the technological relevance of UF in a wide range of applications, its one limitation is flux decline due to fouling. Fouling is an irreversible process caused by solute adsorption and pore blocking, which can be minimized by using more hydrophilic membrane components. The performance of the polymeric membranes can be improved by blending the original polymer components with other polymers which having more suitable properties. The blending process of polymers is a very interesting way for producing materials with improved bulk properties of membranes. In order to improve the pure water flux of UF of PVC membranes, some hydrophilic polymers such as polyvinyl chloride-co-vinyl acetate (VC-co-VAC), CEVA, poly(methyl methacrylate) (PMMA), poly vinylidene fluoride (PVDF), SAN, IB-co-MIL PAN, poly (butyl acrylate) (PBA), chlorinated polyvinyl chloride (CPVC), and polyvinyl pyrrolidone (PVP) were blended previously with PVC for water treatment purposes. Although acrylonitrile butadiene rubbers are miscible with PVC, because of their poor hydrophilicity, the performance of the produced liquid-separated membranes is not very good. Unlike acetyl cellulose is a hydrophilic polymer, and it is useful for blending with PVC to improve the hydrophilicity of UF membranes [5].In a lab scale study, membranes made from PVC exhibited higher permeate fluxes and lower salt rejections [4]. The addition of organic components as an additive to casting solution has been regarded one of the best frequently techniques used in membrane preparation. However, the role of various organic additives such as methyl cellulose, glycerin, polyvinyl pyrrolidone (PVP), or poly (ethylene glycol) in casting solution has been reported as a pore-forming agent for enhancing permeation properties [6-11].

The main problem in blending polymers process is that most polymer pairs are rather immiscible. The miscibility of polymers occurs in three situations and can be described as follows: (1) polymers of low molecular weights that no longer have negligible entropy of mixing,(2) polymers that are chemically very similar and have a very small unfavorable heat of mixing, and (3) polymers that show specific interactions between the molecules, resulting in a favorable heat of mixing. But it is not easy to predict the miscibility of polymers. Immiscible blends are known for their poor mechanical properties that are due to poor adhesion between their polymer domains. Furthermore, the acting force between the polymer and separated matter (usually water) must be taken into account that represents hydrophilicity character. The modification of PVC can generally be achieved by nucleophilic substitution reactions of chlorine atoms. Appropriate modification agents are characterized by a strong nucleophile character, while their basicity should be low in order to avoid dehydro-chlorination [12, 13]. If modification of the polymer is carried out in order to introduce functional groups, [14] which can also react by a substitution mechanism, a second type of side reaction may occur, which is the crosslinking of the polymeric chains. To avoid crosslinking, the modification reaction has to be performed with a selective bi-functional molecule. The functionalization of PVC with amino groups is an objective pursued by scientists for more than 10 years [15-18].The general approach to achieve this aim was the use of aliphatic diamines compounds. This might cause problems due to the elevated basicity of these compounds. Furthermore, the absence of selectivity of the modification agents forced the substitution reaction to be stopped at relatively low conversion to limit cross linking. The preparation of aminated polymers is of great industrial interest due to potential applications as polymeric proton-selective electrode materials or membranes for gas separation. In this respect, polyvinyl chloride (PVC) is an especially attractive polymer because of its excellent film-forming and reported membrane properties.

The objectives of this study were to describe the synthesis and characterization of aminated PVC using a new procedure for water treatment applications and also for evaluating the modified membrane performance in terms of permeability (pure water flux) and quality (salt rejection).

\section{Experimental Part}

\subsection{Materials}

Polyvinyl chloride (M.wt. 48000, fine powder) was imported from Belami fine chemicals. (India).Sodium chloride (Purity 99.5\%, M.wt.58.44) was obtained from Sigma-Aldrich Chemicals Ltd. Germany. Tetrahydrofuran (THF) (Purity 99.9\%, distilled) was purchased from Sisco research laboratories, India..Poly (ethyleneimine) (M.wt. 50.000 -100.000) was obtained from MP Biomedicals, Inc. Egypt.

\subsection{Preparation of PVC-g-PEI Membranes}

PVC and the blended membranes of PVC-g-PEI were prepared by the solvent evaporation method. PVC-g-PEI (3\%, $\mathrm{w} / \mathrm{v})$ was dissolved in THF/ethanol as a solvent casting solution mixture at $25{ }^{\circ} \mathrm{C}$. After addition of PEG to the mixture with continuous stirring for $5 \mathrm{~h}$, the solution was casted on a horizontal glass plate at $25^{\circ} \mathrm{C}$ and, after a predetermined evaporation time ranging from $72-96 \mathrm{hrs}$. The PVC-g-PEI membrane was removed gently from the glass plate and soaked in distilled water for $2 \mathrm{hrsfor}$ removing any traces of solvent and also leave the glass plate smoothly. By changing the concentration of the polymer in the casting solution and the ratio between PVC and PEI, dissimilarity morphology properties, permeation, and transport properties could be observed. The average thickness of obtained membranes was 0.07-0.09 $\mathrm{mm}$. Dry membranes were obtained by means of dehydrating the wet membranes to scale the wetting angle of PVC and blended membranes of PVC-g-PEI. 


\subsection{Instrumental Measurements}

\subsubsection{Wet-Ability Measurements}

Specimens PVC-g-PEI membranes $(1 \mathrm{~cm} \times 1 \mathrm{~cm})$ at random position were used for wet-ability measurements. Contact angles of PVC-g-PEI surfaces were measured with water drop on the surface of membranes by the contact angle meter, the average value of five measurements was taken at different locations on the surface. The hydrophilicity of the membrane is often measured through contact angle. It is one of the simplest available methods for determining the hydrophobic or hydrophilic nature of chemical groups attached to the outer layer of a surface [20].

The swelling ratio or water uptake (WU) was determined by soaking the membrane samples in de-ionized water for $24 \mathrm{~h}$ at room temperature until swelling equilibrium was carried out. Samples were removed and the excess liquid adhered to both sides of their surfaces was quickly blotted by filter paper. The water uptake was determined as the weight of the membrane in the wet state compared to the dry state using Eq. (1).

WU $(\%)$ or swelling ratio SR $(\%)=\left(\mathrm{W}_{\mathrm{w}}-\mathrm{W}_{\mathrm{d}}\right) / \mathrm{W}_{\mathrm{d}} \times 100$ Eq. (1)

Where $W_{\mathrm{d}}$ and $W_{\mathrm{w}}$ are the weights of the dry and the wet membrane samples respectively [19].

\subsubsection{Determination of Flux and Separation Rate}

PVC-g-PEI membranes were tested in the membrane cell after pressurized under a pure water pressure of $200 \mathrm{KPa}$ for $1 \mathrm{~h}$. The pure water flux, permeation flux, and the rejection were then measured under the pressure of $200 \mathrm{Kpa}$ to $600 \mathrm{Kpa}$ at $20{ }^{\circ} \mathrm{C}$. Thepure water flux (PWF) and permeation flux $(\mathrm{F})$, were calculated using equation 2 [21].

$$
F(\mathrm{PWF})=\mathrm{W} / \mathrm{At}
$$

Where the total weight of the water or solution permeated during the experiment; $A$ is the membrane area, and $t$ is the operation time.

Rejection, Rwas calculated using equation 3 [20].

$$
R(\%)=\left(1-C p / C_{\mathrm{f}}\right) \times 100 E q .
$$

Where $C_{\mathrm{p}}$ and $C_{\mathrm{f}}$ are the concentrations of permeate and feed respectively. After filtration process, the whole test apparatus and the membrane sheet were rinsed thoroughly with de-mineralized water to remove any deposition.

\subsubsection{Investigation of Surface Roughness}

The surface roughness investigation of the PVC and PVC-g-PEI membranes used for water treatment applications is very important characterization tool. The average roughness was measured using surface roughness tester SJ- 201P, Japan. Samples were mounted onto a glass slide with double-sided tap. Minimum sample dimensions were $25 \mathrm{~mm} \times 25 \mathrm{~mm}$.

\subsubsection{Determination of Ionic Exchange Capacity (IEC)}

The IEC determination was performed using the titration method. For the IEC measurements, the membranes in acid form $\left(\mathrm{H}^{+}\right)$was converted into $\mathrm{Na}^{+}$form by immersing in $1 \mathrm{M}$ of $\mathrm{NaCl}$ solution to liberate the $\mathrm{H}^{+}$ions. $\mathrm{H}^{+}$ions in solution were then titrated with $0.01 \mathrm{M} \mathrm{NaOH}$ and phenolphthalein indicator. The IEC is calculated from equations were discussed elsewhere [22-29].

$$
\mathrm{IEC}=(\mathrm{VNaOH} \times \mathrm{CNaOH}) / \mathrm{W}
$$

Where $\mathrm{V}$ is the volume of consumed $\mathrm{NaOH}$ solution and $\mathrm{C}$ is the concentration of $\mathrm{NaOH}$. W is dried membrane weight.

\subsection{Membrane Characterizations}

\subsubsection{FT-IR}

Vacuumed and dried samples of PVC, (PVC-g-PEI), and (PVC-g-PEI with PEG) membranes were analyzed by FTIR on an EQUINOX 55 instrument (BRUKER, Germany).Translucent $\mathrm{KBr}$-disks were prepared by grinding the dried sample materials together with infrared grade $\mathrm{KBr}$ and then pressing. The FTIR spectra were obtained by recording clear deformation vibration after blending for PEI and PEG with PVC. All samples were freeze-dried using liquid nitrogen, crushed to a fine powder $(\mathrm{KBr}$ : sample $=130$ $\mathrm{mg}$ : $2 \mathrm{mg}$ ), and pressed by applying a force $105 \mathrm{~N}$ into a transparent disk (maximum disk weight $=145 \mathrm{mg}$ ) with a diameter of $13 \mathrm{~mm}$. All samples were measured in absorbance mode.

\subsubsection{Thermal Stability by $T G A$}

The thermal characterization of vacuumed-dried of PVC, (PVC-g-PEI), and (PVC-g-PEI with PEG) membranes have been accomplished using TGA and DSC thermo-grams. The thermo-gravimetric analysis (TGA) was performed on a 204 Phoenix TGA instrument (NETZSCH, Germany) from 50 to $600^{\circ} \mathrm{C}$ at a heating rate of $10{ }^{\circ} \mathrm{C} / \mathrm{min}$. The onset temperature (Tonset) was determined by TGA thermo-grams. Tonset is defined as the temperature at the intersection of the baseline mass and tangent drawn to the mass curve at the inflection point or point of greatest rate of mass loss \% [30].

\subsubsection{Mechanical Properties (Universal Mechanical Testing Machine)}

The maximum tensile strength and the elongation degree to break PVC, (PVC-g-PEI), and (PVC-g-PEI with PEG) membranes have been conducted using a tensile test machine (model: AG-I/50-10KN, Japan). PVC, (PVC-g-PEI), and (PVC-g-PEI with PEG) membranes were cut into specific shape (40 mm long, $15 \mathrm{~mm}$ wide). The analysis was performed at a stretching rate of $10 \mathrm{~mm} / \mathrm{min}$ with pre-load of $0.5 \mathrm{~N}$ to determine load for each sample [31]. The thickness of membrane samples was measured with a dogmatic caliper before examination.

\subsubsection{Scanning Electron Microscope (SEM)}

The surface and internal structure of the prepared membranes samples were investigated by Analytical-SEM (type: JEOL, JSM-6360LA, Japan) with $15 \mathrm{kV}$ voltage for secondary electron imaging. The samples were all dried in vacuum at room temperature, then frozen in liquid nitrogen and fractured. After plated with gold they were transferred 
into the microscope. Membranes were dehydrated by freeze-dryer and coated with Au using an ion sputter coater in (model: 11430, USA, combined with vacuum base unit or SPi module control, model: 11425, USA.

\section{Results and Discussion}

In order to prepare polymer blend membranes with suitable pore size, the effect of different additive types such as inorganic, organic, and macromolecular nature as pore former on pure water flux PVC and the blended membranes of PVC/PEI were attempted. Thus, different pore formers such as glycerol, (ethylene glycol) (EG), or poly (ethylene glycol)(PEG) as additives; could be used individually at different concentrations in the casted solution. PEG has been used as pore former in this work.

\subsection{Mechanical Properties}

The mechanical properties of PVC membranes with different Concentration of PVC were determined from critical breaking point of stretching pieces. It is shown in figure 1.

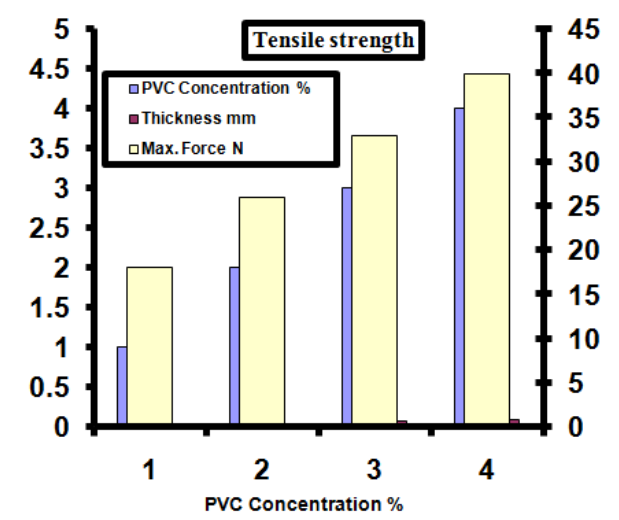

Figure 1. the increasing of Mechanical properties and force via PVC content.

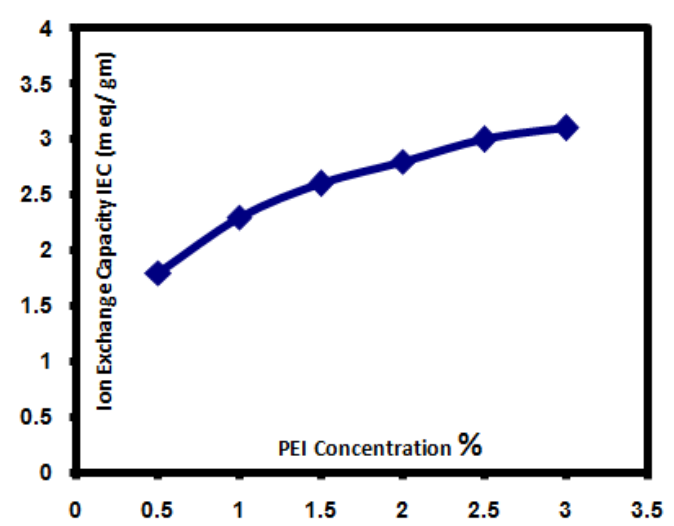

Figure 2. Ion exchange capacity of PVC-PEI blend membranes $(3 \% P V C+1 \%$ $\mathrm{PEI}+750 \mu \mathrm{l} \mathrm{PEG}$ ), R.T, $3 \% \mathrm{Nacl}$

\subsection{Effect of Poly Ethylene Imine Concentration}

\subsubsection{Ion Exchange Capacity}

The effect of PEI contents in PVC-g-PEI membranes on ion exchange capacity was measured and illustrated in Figure2.
Different amount of PEI from $0 \%$ to $3 \%$ was employed. It was shown a clear increasing from 0 to $2 \%$ of PEI that was attributed to increase the amine content of the prepared membrane, beyond this concentration slightly increasing in ion exchange capacity was observed. In fact, the compatibility of PVC and PEI solution start to decrease result increase the hydrophilicity of solution which case a fast solution out of one of both polymer (PEI) from the reaction medium that can recognized by precipitation of PEI outside the reaction medium and removed during washing step.

\subsubsection{Water Uptake}

The influence of different portions of PEI on membranes wet-ability was studied as shown in figure 3 . It illustrates swelling behavior of PVC-g-PEI have improved dramatically with increasing the added amounts of PEI. This behavior can be attributed to increase the hydrophilicity of membranes by increasing the amount of PEI. Also it is clear that the effect of PEG addition on water uptake behavior of PVC-g-PEI membranes. At high concentration of PEI, precipitation of PEI and removing it in washing step generated a larger amount of micro pours that imbibe a large percent of water Figure 4.

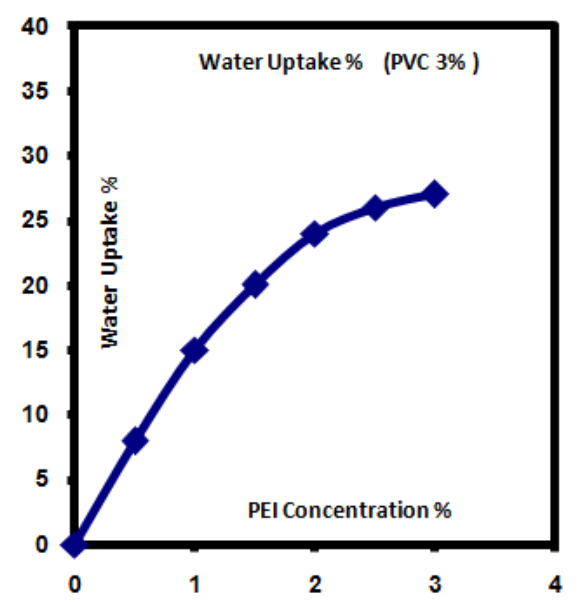

Figure 3. Water uptake of PVC-PEI blend membranes.

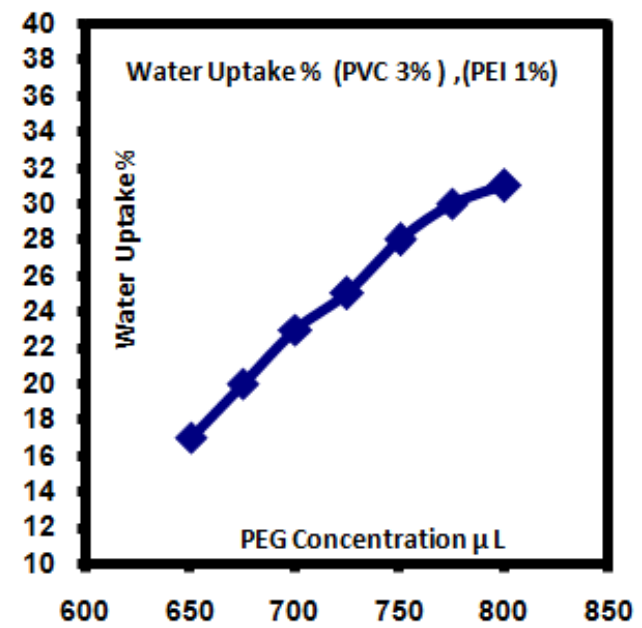

Figure 4. Water uptake of (PVC-PEI-PEG) blend membranes. 


\subsubsection{Surface Roughness}

Surface roughness of PVC and PVC-PEI membranes were measured and recorded Figure (3.9).It is clear that the roughness increase by increasing the PVC content in the membrane, while The results show decrease of surface roughness of membranes by increasing PEI concentration, due to the interaction between hydrophilic polymer (i.e.; PEI) and hydrophobic polymer (i.e.; PVC). The figure showed also increase of roughness of membranes at lower surface than that of upper surface especially in high concentration of PEI. This observation can be explained by partially precipitation for PEI from solution during casting and solvent evaporation process and removed in washing step to generate a highly rough pours surface.
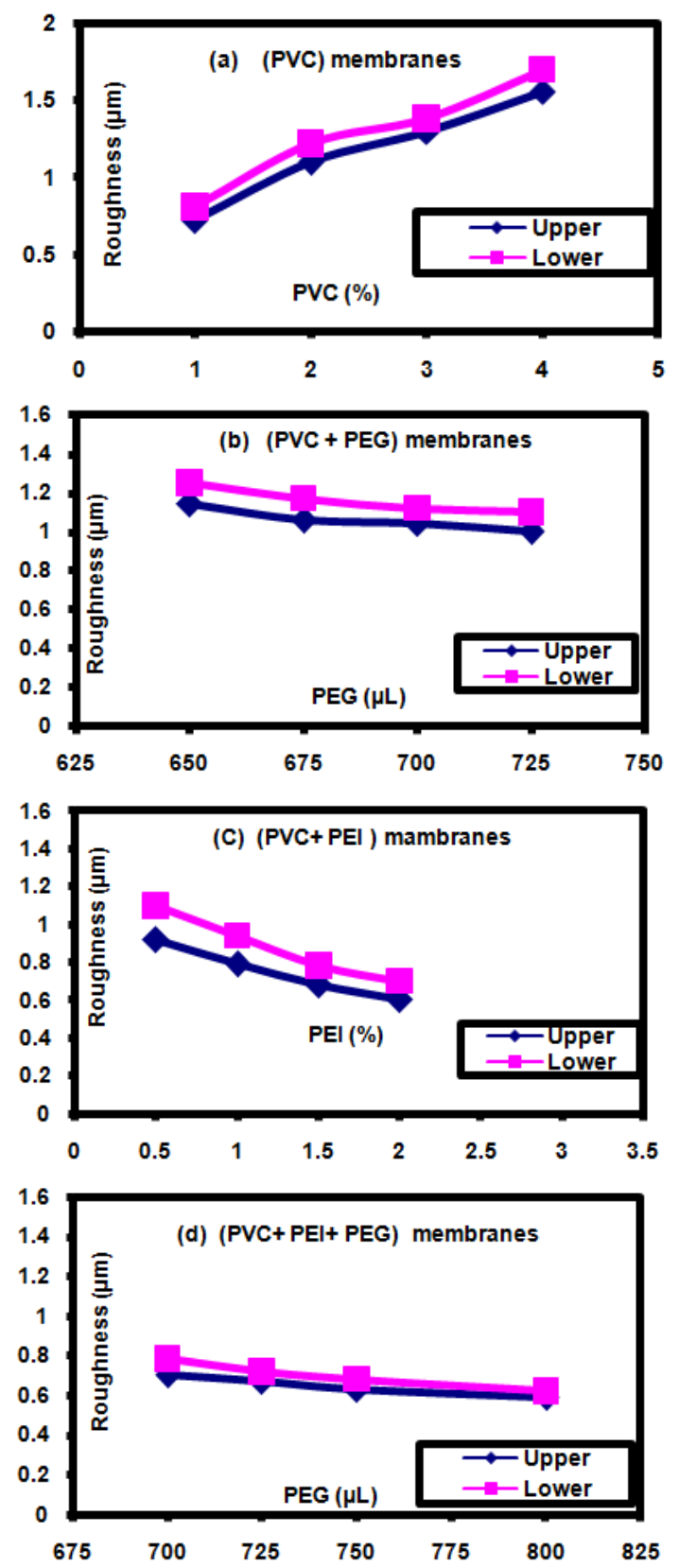

Figure 5. Surface roughness of PVC and modified PVC membranes.

\subsubsection{Effect of Activation Temperature $\left({ }^{\circ} \mathrm{C}\right)$ on Salt \\ Rejection (\%)}

It is shown from the figure 6 the effect of activation temperature on salt rejection $\%$, where the efficiency of PVC-g-PEI was enhanced gradually for sodium chloride removal $(\%)$ at $20-45^{\circ} \mathrm{C}$. This is due to more compatibility of copolymers PVC-g-PEI membranes. Whereas, a slight increment in salt rejection (\%) was shown at $45-50{ }^{\circ} \mathrm{C}$.

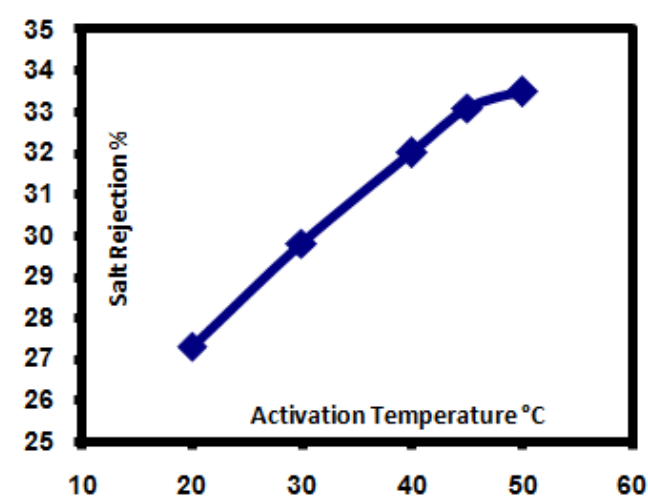

Figure 6. Effect of Activation Temperature ${ }^{\circ} \mathrm{C}$ on Salt Rejection $\%(3 \%$ PVC $+1 \%$ PEI+750 $\mu \mathrm{l}$ PEG), R.T, $3 \% \mathrm{Nacl}$

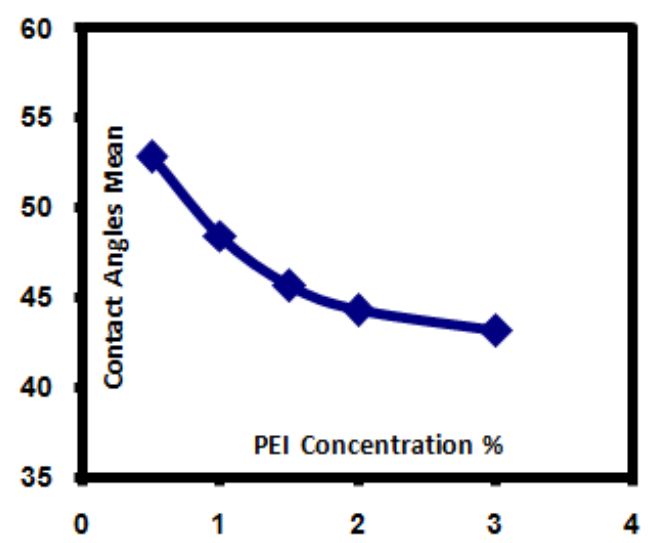

Figure 7. Contact Angles for membrane Samples $(3 \%$ PVC+750 $\mu \mathrm{l}$ PEG)

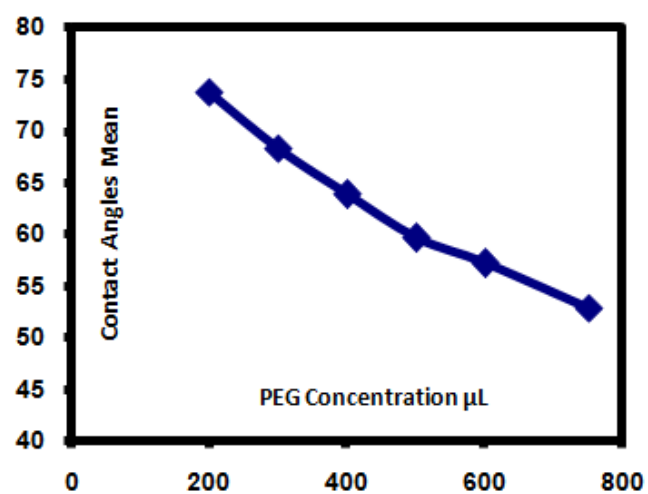

Figure 8. Contact Angles for membrane Samples $(3 \%$ PVC $+1 \% P E I)$

\subsubsection{Wet-Ability}

On the other side, the surface wet-ability of PVC-g-PEI membranes was determined using contact angle measurement. Figures $7 \& 8$ showed the contact angle values of PVC-g-PEI 
membranes in functions with PEI and PEG different concentrations, respectively. The results revealed that the values of membrane surface contact angles significantly decreased with increasing either PEI or PEG, due to increasing the hydrophilic characteristics of PVC-g-PEI membranes.

\subsubsection{Effect of Pressure on the Salt Rejection and Conductivity}

The effect of different pressure values on salt rejection (\%) and conductivity values was explored in figure 9.The results revealed that the values of conductivity surface contact angles significantly increased and salt rejection decreased with gradually increasing for pressure.

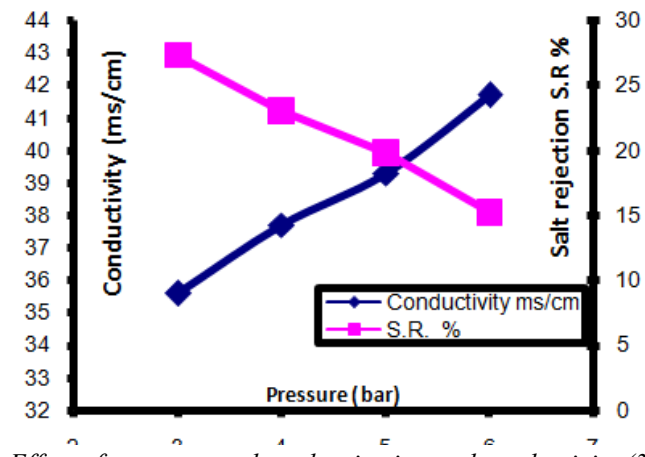

Figure 9. Effect of pressure on the salt rejection and conductivity $(3 \% \mathrm{PVC}+$ $1 \% \mathrm{PEI}+750 \mu \mathrm{lPEG}$ ), R.T, 3\% Nacl

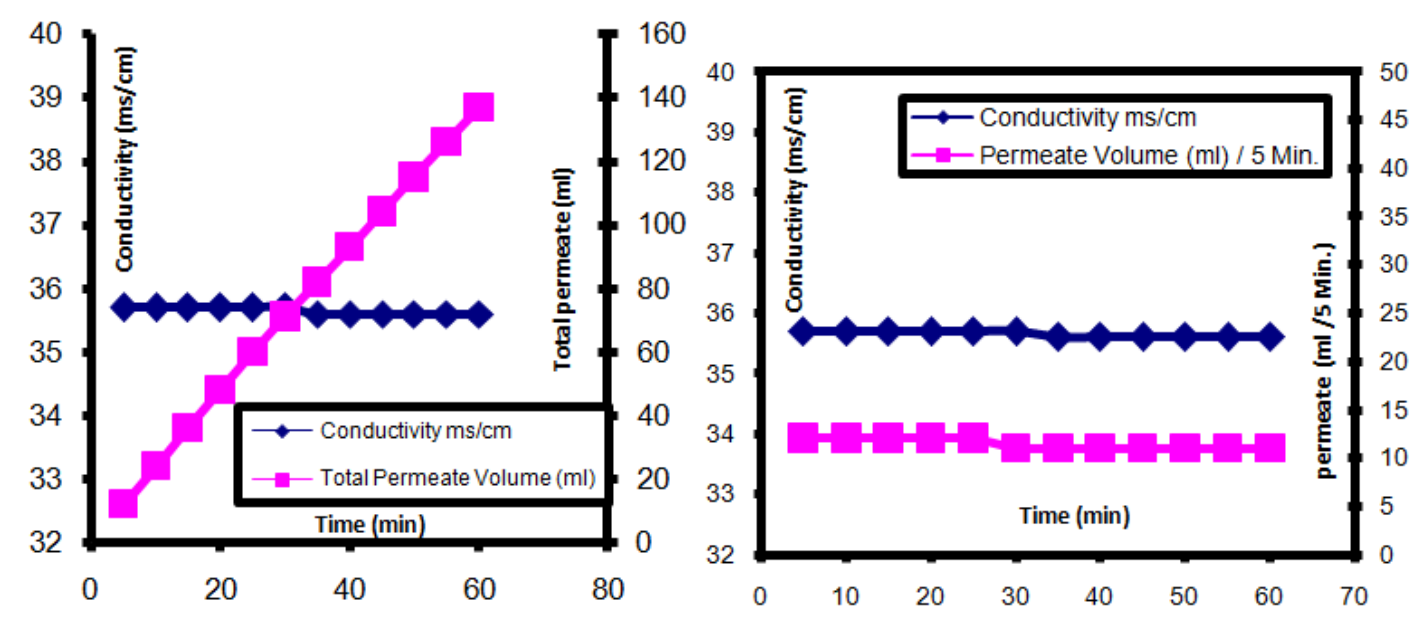

Figure 10(A, B). The permeate flux and Conductivity $(3 \%$ PVC $+1 \%$ PEI+750 $\mu$ l PEG), $(2-3$ bar $)$, R.T, $3 \%$ Nacl, S.R $\% \sim 27.3 \%$

\subsubsection{The Permeate Flux and Conductivity}

It is shown from the figure $10(\mathrm{~A} \& \mathrm{~B})$, The flux and the conductivity of the permeate with time.

\subsection{Characterization}

\subsubsection{FT-IR Characterization}

\subsubsection{FT-IR Spectra of PVC and PVC-PEI Membranes}

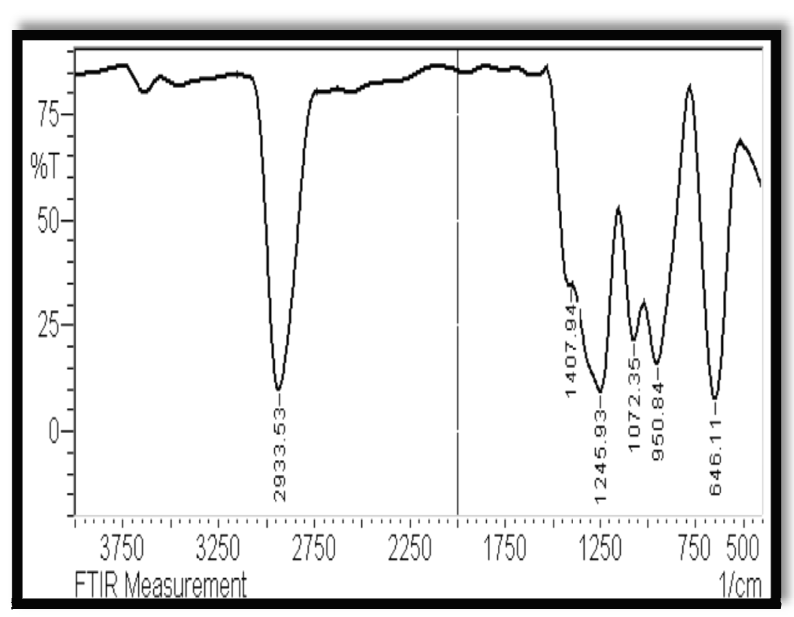

Figure 11. FT-IR of (3\% PVC) membrane

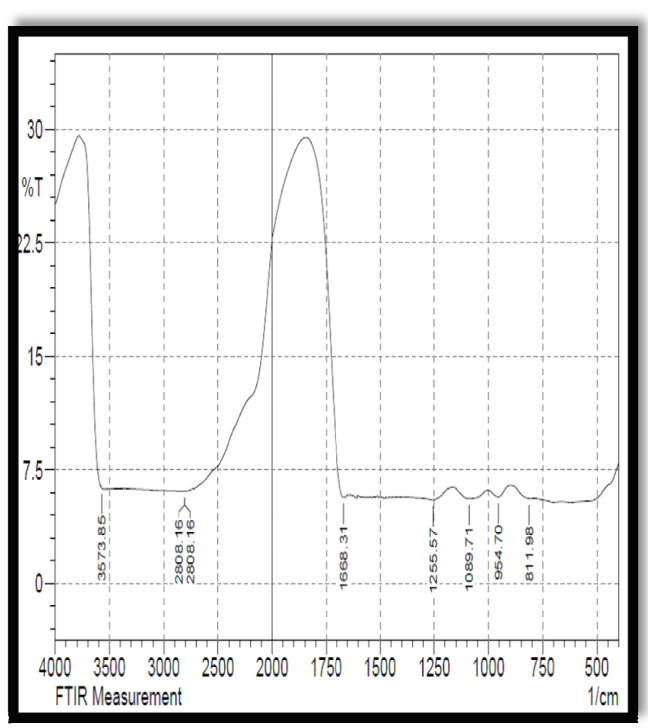

Figure 12. FT-IR of (3\% PVC+ $1 \%$ PEI) membrane

The FT-IR spectra of PVC and PVC-PEI membranes are shown. In PVC spectra figure 11, it can be seen that $\mathrm{C}-\mathrm{H}$ stretching peak was observed at $2933 \mathrm{~cm}^{-1}, \mathrm{CH}_{2}$ deformation mode at $1407 \mathrm{~cm}^{-1}, \mathrm{C}-\mathrm{H}$ rocking mode at $1245 \mathrm{~cm}^{-1}$, trans $\mathrm{C}-\mathrm{H}$ wagging mode at $1072 \mathrm{~cm}^{-1}, \mathrm{C}-\mathrm{Cl}$ stretching mode at $950 \mathrm{~cm}^{-1}$, and cis $\mathrm{C}-\mathrm{H}$ wagging mode at $646 \mathrm{~cm}^{-1}$. After blending figure 12 , a broad band was generated at 3200-3600 
$\mathrm{cm}^{-1}$ corresponding stretching of $-\mathrm{NH}_{2}$ and $-\mathrm{NH}$ - groups associated with poly (ethylene imine). The band at $1635 \mathrm{~cm}^{-1}$ corresponds to deformation vibration of $-\mathrm{NH}_{\mathrm{n}}$ in plane. The band at $1568 \mathrm{~cm}^{-1}$ corresponds to deformation vibration of groups $-\mathrm{NH}-$ of amines.

The bands at 1448 and $1257 \mathrm{~cm}^{-1}$ correspond to deformation vibration of $\mathrm{C}-\mathrm{N}$ and the band at $1081 \mathrm{~cm}^{-1}$ corresponds to asymmetric stretching of $\mathrm{C}-\mathrm{N}-\mathrm{C}$ which has very fied the grafting process between PVC and PEI.

\subsubsection{FT-IR Spectra of (PVC+PEI+PEG) Membrane}

It is clear from the figure13, the presence of $\mathrm{OH}$ group of PEG and amino groups ( $\mathrm{NH} \& \mathrm{NH}_{2}$ )of PEI.

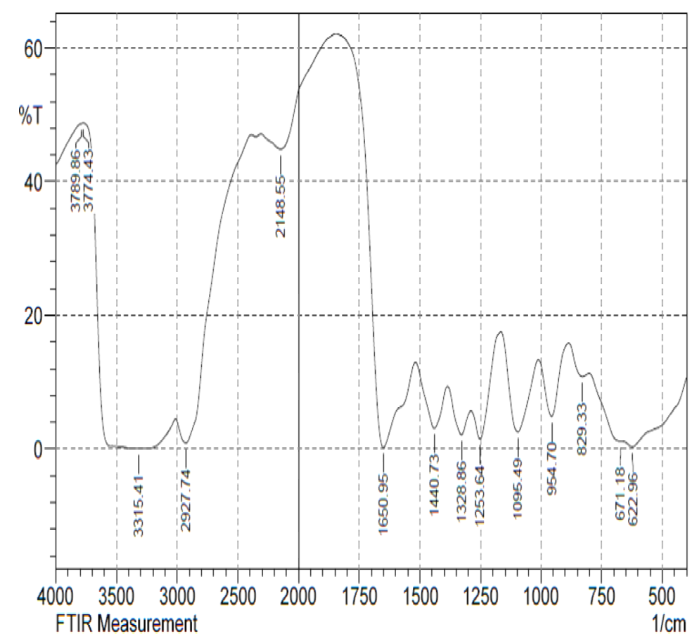

Figure 13. FT-IR of (3\% PVC + 1\% PEI + $750 \mu L P E G)$ membrane

\subsubsection{Thermal Gravimetric Analysis (TGA)}

Thermal gravimetric analysis of PVC and PVC-g-PEI were performed. The data of TGA are listed in table 1 and illustrated by figures 14-16.

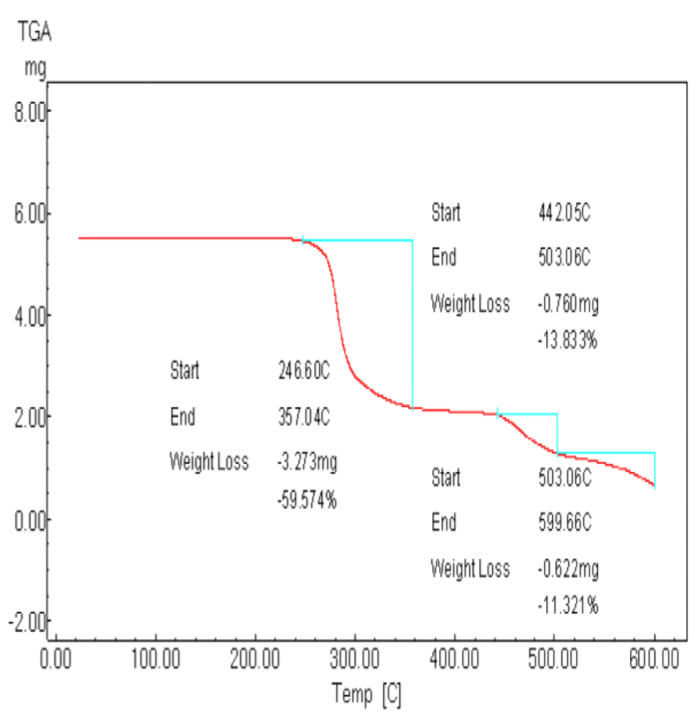

Figure 14. TGA of (3\% PVC) membrane

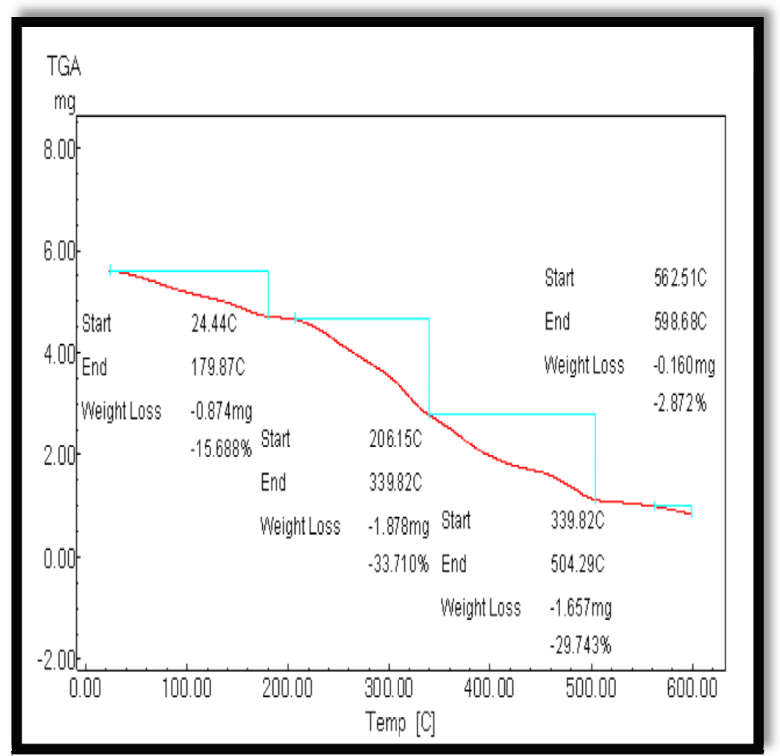

Figure 15. TGA of $(3 \%$ PVC $+1 \%$ PEI) membrane

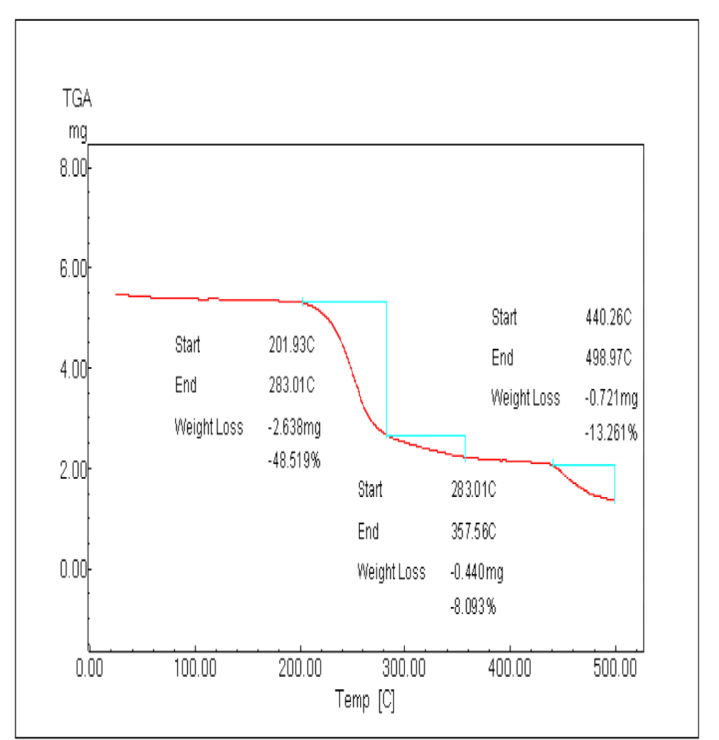

Figure 16. TGA of $(3 \% P V C+1 \% P E I+750 \mu L P E G)$ membrane

Table 1. Thermal properties of PVC-g-PEI blend xerogels according to TGA thermo-gram results.

\begin{tabular}{lccl}
\hline $\begin{array}{l}\text { TGA results } \\
\text { PEI content } \\
(\%)\end{array}$ & $\begin{array}{c}\mathbf{T}_{\mathbf{d}} \text { at weight } \\
\text { loss } \mathbf{5 0 \%},{ }^{\mathbf{O}} \mathbf{C}\end{array}$ & $\mathbf{T}_{\text {onset, }}{ }^{\circ} \mathbf{C}$ & $\begin{array}{l}\text { Second degradation } \\
\text { stage }\end{array}$ \\
\hline 0 & 248 & 245 & $246-357$ \\
0.5 & 301 & 250 & $205-319$ \\
1 & 340 & 243 & $206-340$ \\
1.5 & 382 & 239 & $210-377$ \\
2 & 371 & 221 & $210-373$ \\
3 & 300 & 218 & $196-302$ \\
4 & 291 & 225 & $197-285$ \\
\hline
\end{tabular}

The thermal degradation of PVC-g-PEI membrane xerogels was conducted using TGA thermal analyzer as depicted in table 1 . The thermal onset decomposition temperature $\left(\mathrm{T}_{\text {onset }}\right)$ and the decomposition temperature $\left(\mathrm{T}_{\mathrm{d}}\right)$ at weight loss $(50 \%)$, and the sharp thermal degradation stage were discussed in 
details to describe the thermal decomposition behavior of PVC-g-PEI as function of PEI contents in membranes. Results shows thermal stability of PVC-g-PEI membranes were improved with increasing PEI content till $1.5 \%$, and then it degraded quickly.

This phenomenon can be ascribed to the interaction between two moieties of hydrophilic and hydrophobic polymer of PEI and PVC, respectively up to $1.5 \%$ PEI, after this concentration the hydrophilicity characteristic of PVC-PEI membranes might cause quick thermal degradation as shown in $\mathrm{T}_{\mathrm{d}}$ at weight loss $50 \%$.

Similarly, the sharp degradation stage followed the same trend with PEI concentration. Maximum $\mathrm{T}_{\mathrm{d}}$ values were improved till PEI content of $1.5 \%$, and then thermally collapsed with higher PEI contents of 2,3 , and $4 \%$.

\subsubsection{Scan Electron Microscope for PVC and Modified PVC Membrane}

The surface morphology was investigated using SEM. Figure 17, 18 and 19 represents the morphology changes due to additions of PEI and PEG. Presented images show presence of pores and internal channels formation with increasing PEI and PEG as pore forming.
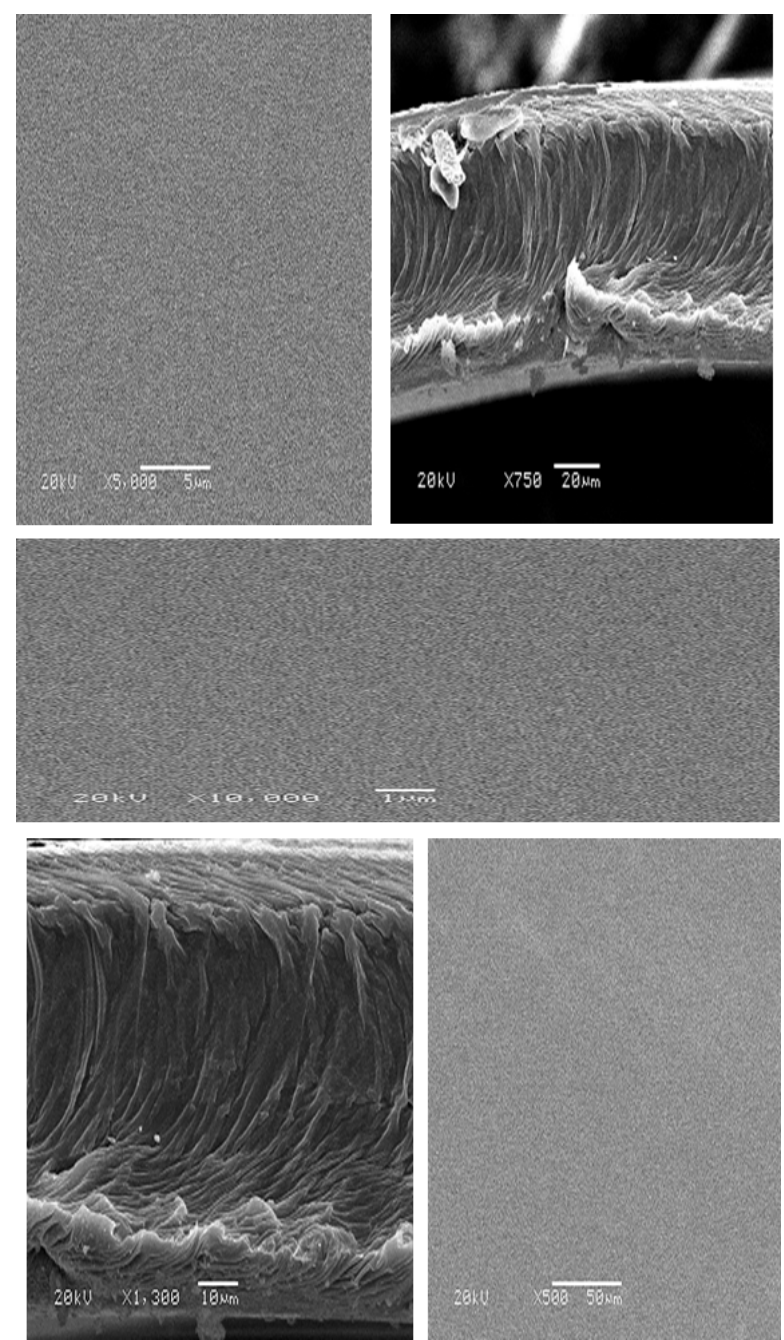

Figure 17. Scan electron Microscope of surface of $(3 \%$ PVC)
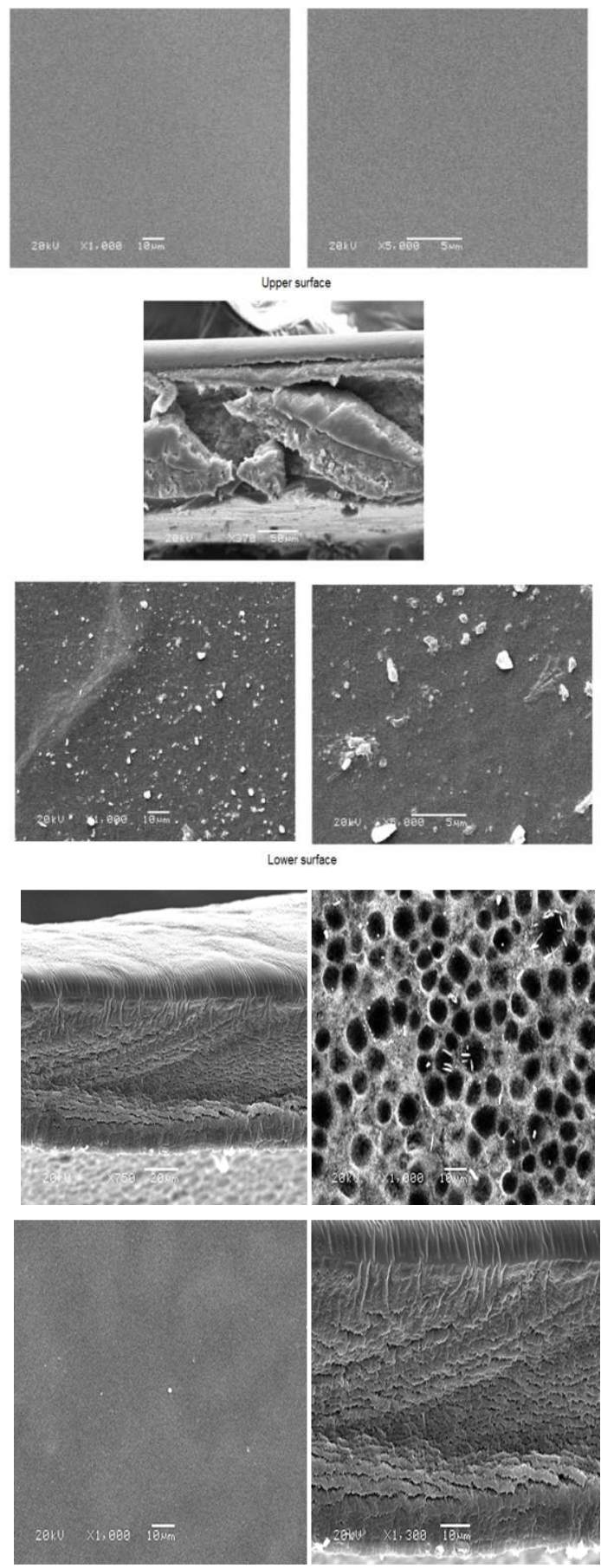

Figure 18. Scan electron Microscope of surface of $(3 \%$ PVC $+1 \%$ PEI) membrane

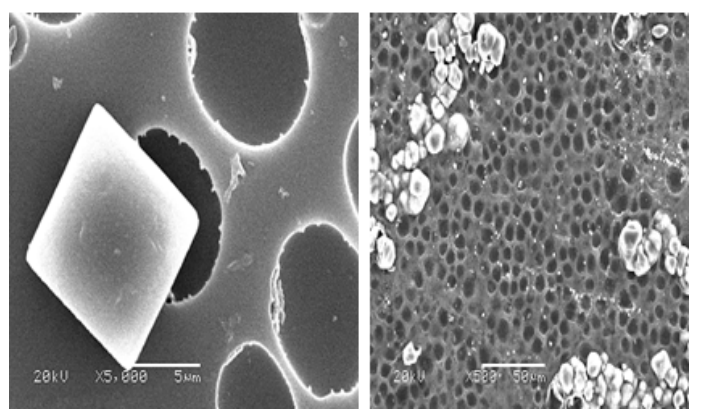

Figure 19. (3\% PVC + 1\% PEI + $750 \mu L P E G), 3 \%$ Nacl application 


\section{References}

[1] M. Al-Sofi, A. Hassan, G. Mustafa, A. Dalvi, M. Kither, Nanofiltration as ameans of achieving higher TBT of $\geq 120^{\circ} \mathrm{C}$ in MSF. Desalination 1998,118 123-129

[2] Shim, J. K.; Na, H. S.; Lee, Y. M.; Huh, H.; Nyo, Y. C. J Membr.Sci 2001, 190, 215.

[3] Kang, J. S.; Shim, J. K.; Huh, H.; Lee, Y. M. Langmuir 2001, $17,4352$.

[4] JianXu, Zhen-Liang Xu, Poly(vinyl chloride) (PVC) hollow fiber ultrafiltration membranes prepared from PVC/additives/solvent, Journal of Membrane Science 208 (2002) 203-212

[5] Yuelian Peng*, Yan Sui,Compatibility research on PVC/PVB blended membranes, Desalination 196 (2006) 13-21

[6] Kim, J. H.; Lee, K. H. J MembrSci 1998, 138, 153.

[7] Young, T. H.; Chen, L. W. Desalination 1995, 103, 233.

[8] Munori, S.; Bottino, A.; Capannel, G.; Moretti, P.; Petit Bon, P. Desalination 1988, 70, 265.

[9] Kesting, R. E.; Fritzsche, A. K.; Murphy, M. K.; Cruse, C. A. Handermann, A. C.; Malon, R. F.; More, M. D. J ApplPolymSci1988, 35, 1769.

[10] Kraus, M. A.; Nemas, M.; Frommer, M. A. J ApplPolymSci1979, 23, 445.

[11] Chuang, W. Y.; Young, T. H.; Chiu, W. Y.; Lin, C. Y. Polymer2000, 41, 5633.

[12] Starnes, W. H.; Plitz, I. M. Macromolecules 1976, 9,633.

[13] Shapiro, J. S.; Starnes, W. H.; Plitz, I. M.; Hische, D. C. Macromolecules 1986, 19, 230.

[14] Reinecke, H.; Mijangos, C. Polym Bull 1996, 36, 13.

[15] Kusy, R. P.; Whitley, J. Q.; Buck, R. P.; Cosofret, V. V.; Lindner, E. Polymer 1994, 35, 2141.

[16] Ma, S.-C.; Chaniotakis, N. A.; Meyerhoff, M. E. Anal Chem 1988, 60, 2293.

[17] Ma, S.-C.; Meyerhoff, M. E. MikrochimActa (Wien) 1990, 1, 197.

[18] Cosofret, V. V.; Lindner, E.; Buck, R. P.; Kusy, R. P.; Whitley, J. Q. J Electroanal Chem 1993, 345, 169.

[19] Garry Nathaniel B. Barõna, Bong Jun Cha, Bumsuk Jung., Negatively charged poly(vinylidene fluoride) microfiltration membranes by sulfonation, Journal of Membrane Science 290 (2007) 46-54.
[20] L. Palacio, J.I. Calvo, P. Pradanos, A. Hernandez, P. Vaisanen, M. Nystrom, Contact angles and external protein, adsorption onto UF membranes, J. Membr. Sci. 152 (1999) 189.

[21] Chunrui Wu, Shouhai Zhang, Cheng Liu , Daling Yang , XigaoJian, Preparation, characterization and performance of thermal stable poly(phthalazinone ether amide) UF membranes, Journal of Membrane Science 311 (2008) 360-370.

[22] S. M. Hosseini, S. S. Madaeni, A. R. Khodabakhshi, Preparation and characterization of ABS/HIPS heterogeneous cation exchange membranes with various blend ratios of polymer binder, Journal of Membrane Science 351 (2010) 178-188.

[23] R. K. Nagarale, V. K. Shahi, R. Schubert, R. Rangarajan, R. Mehnert, Development of urethane acrylate composite ion-exchange membranes and their electrochemical characterization, Journal of Colloid and Interface Science 270 (2004) 446-454.

[24] X. Li, Z. Wang, H. Lu, Zhao Chengji, H. Na, Zhao Chun, Electrochemical properties of sulfonated PEEK used for ion exchange membranes, Journal of Membrane Science 254 (2005) 147-155.

[25] T. Sata, Ion exchange membranes: preparation, characterization, modification and application, The Royal Society of Chemistry, Cambridge, United Kingdom, 2004.

[26] S. M. Hosseini, S. S. Madaeni, A. R. Khodabakhshi, Preparation and characterization of $\mathrm{PC} / \mathrm{SBR}$ heterogeneous cation exchange membrane filled with carbon nanotubes, Journal of Membrane Science 362 (2010) 550-559.

[27] S. M. Hosseini, S. S. Madaeni, A. R. Khodabakhshi, Heterogeneous cation exchange membrane: preparation, characterization and comparison of transport properties of mono and bivalent cations, Separation Science and Technology 45 (2010) 2308-2321.

[28] S. M. Hosseini, S. S. Madaeni, A. R. Khodabakhshi, Preparation and characterization of heterogeneous cation exchange membranes based on S-poly vinyl chloride and polycarbonate, Separation Science and Technology 46 (2011) 794-808.

[29] Y. Tanaka, Ion Exchange Membranes: Fundamentals and Applications, Membrane Science and Technology Series, 12, Elsevier, Netherlands, 2007.

[30] Kamoun, E. A., Menzel, H., 2012. HES-HEMA nanocomposite polymer hydrogel: swelling behavior and characterization. J. Polym. Res. 19, 9851-9865.

[31] Alencar, D.Q.H., Humberto, G.F., Gustavo, A.A., Maria, M.F., Antonio, L.B., Julio, S.R., 2003. Development of new hydroactive dressings based on chitosan membranes: characterizations and in vivo behavior. J. Biomed. Mater. Res. 64A, 147-154 